\title{
Catalytically active and corrosion resistant cobalt- based thin films
}

\section{Clara Linder}





\title{
Catalytically active and corrosion resistant cobalt-based thin films
}

\author{
Clara Linder
}

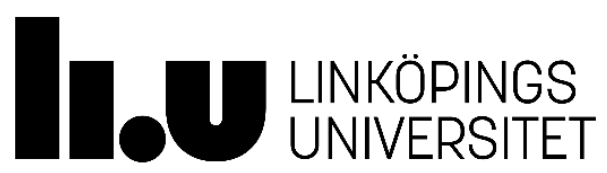

Department of Physics, Chemistry and Biology (IFM)

Faculty of Science and Engineering

Linköpings universitet, SE-581 83 Linköping, Sweden

Linköping 2022 
(C) Clara Linder, 2022

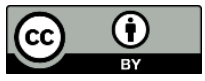

This work is licensed under the Creative Commons Attribution 4.0 International License. To view a copy of this license, visit http://creativecommons.org/licenses/by/4.0/.

Printed in Sweden by LiU-tryck, 2022

ISBN 978-91-7929-216-4 (print)

ISBN 978-91-7929-217-1 (PDF)

https://doi.org/10.3384/9789179292171

ISSN 0280-7971 


\section{Abstract}

Oxygen reduction reaction (ORR) has considerable potential for the production of electricity, issues with water splitting and many other applications in the energy sector. But in order to increase the efficiency of the reaction an electrocatalyst needs to be introduced.

In today's industrial devices precious and costly metals such as platinum (Pt) are used as catalysts. Other more abundant and cheaper alternatives, for example cobalt oxides, are therefore being investigated. In this thesis, pure cobalt $(\mathrm{Co})$ thin films were synthesised to investigate if thin films can be used for the catalysis of ORR. This was successfully carried out by electrochemically modifying the thin films and grow catalytically active hexagonal cobalt oxide nanoparticles.

Multicomponent system $\mathrm{CoCrFeNi}$ is an emerging alloy system with high research interest for its high corrosion resistance suitable for harsh environments in which the applications for ORR are found. In this thesis, $\mathrm{CoCrFe}_{\mathrm{x}} \mathrm{Ni}$ were synthesised as thin films. The corrosion resistance of the films was investigated in addition to their catalytic activity. The effect of Fe content on these properties was also studied. The presence of Fe was crucial for the electrochemical activation of films and catalytic activity towards ORR.

In summary, this thesis shows that cobalt based thin films can be used as catalysts combined with corrosion resistance for ORR applications.

Keywords: Catalysis, oxygen reduction reaction, corrosion, thin film. 


\section{Preface}

This licentiate thesis is part of my doctoral studies in Materials Science at Linköping University (LiU) in the Nanostructured Materials Division of the Department of Physics, Chemistry and Biology (IFM). I was enrolled in the multidisciplinary graduate school Agora Materiae.

During this period, I was employed as a researcher at Research Institutes of Sweden (RISE) in the Corrosion Department, Vehicle and Surface Protection group in Kista, Stockholm.

This work is supported by the Vinnova Competence Centre FunMat-II (grant no 2016-05156), the Vinnova grants no 2018-04291 and no 201904881, and the Centre in Nanoscience and Technology at LiTH, CeNano.

Clara Linder

Stockholm, 2022 


\section{List of appended papers}

Paper 1: Cobalt thin films as water recombination electrocatalysts, Surface \& Coatings Technology 404 (2020) 126643

Authors: Clara Linder, Smita Gangaprasad Rao, Arnaud le Febvrier, Grzegorz Greczynski, Rune Sjövall, Sara Munktell, Per Eklund, Emma M. Björk

Contribution: I was involved in the planning of the work, performed the thin film synthesis and electrochemical characterisation, most of the physical characterisation except for XPS measurements, and wrote the paper with contributions from the co-authors.

Paper 2: Corrosion resistance and catalytic activity towards oxygen reduction of $\mathrm{CoCrFe}_{x} \mathrm{Ni}(0 \leq x \leq 0.7)$ thin films, in manuscript

Authors: Clara Linder, Smita G. Rao, Arnaud le Febvrier, Robert Boyd, Per Eklund, Sara Munktell, Emma M. Björk

Contribution: I was responsible for the planning of the work, performed the thin film depositions, did all characterisation except for the FIB and TEM analysis, and wrote the paper with contributions from the co-authors. 


\section{Acknowledgements}

This work has been supported by many different people with valuable insights who I would like to thank:

Emma Björk, supervisor, for the support and encouragement to a higher research level. You have inspired towards evermore curiosity and a comprehensive understanding of our field.

Sara Munktell, co-supervisor, for being one of the best electrochemists I know. Under your supervision, my knowledge in the field has greatly improved and made me a more competent researcher.

Per Eklund, co-supervisor, your visionary input on the research path that should be taken has helped increase the value of the research we have conducted.

Olivier Rod and Johan Tidblad, colleagues at RISE, grateful to you for the opportunity to start this $\mathrm{PhD}$ journey and to keep it going strong. Without your involvement, it would have been difficult to balance between numerous industrial research projects and my own academic endeavour.

Henrik Pedersen, mentor, for making time if needed to secure my progress.

Björn Mårlid and Rune Sjövall with co-workers, SAFT AB, for the fascinating industrial challenges you have given me, in combination with a truly warm and fantastic collaborative environment.

Members of FunMat-II, for making the Vinnova Competence Centre an excellent research platform, a forum for new brilliant ideas, future challenges and creating collaborations between industry, institutes and academia. A special thank you goes to all the $\mathrm{PhD}$ students within the centre who have supported and helped me in this adventure. 
Vehicle \& Surface Protection group and Nanostructured Materials Division, research units, for welcoming me into your group, involving me in different activities and were open for discussion of my research.

Special thanks go to Smita Rao, Rui Shu, Arnaud le Febvrier for the priceless assistance with the deposition system, Robert Boyd for the incredible help with microscopy and Grzegorz Greczynski for the assistance and discussion of XPS measurements.

Friends and family, even though my research has been almost a complete mystery to you, I have always felt your support.

Martin Vestberg, partner, for constant moral support when I was facing challenges and difficulties. You helped me see my research from another perspective and showed me there are many ways to reach a goal. 


\section{Table of Contents}

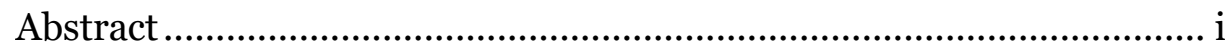

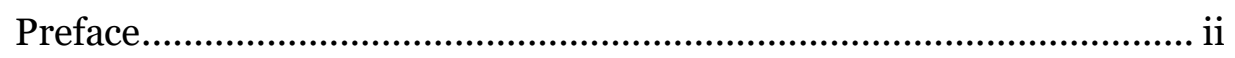

List of appended papers ...................................................................... iii

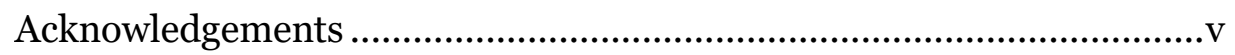

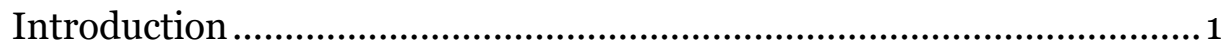

Aims of thesis ................................................................ 2

Electrocatalysis of the reduction of oxygen ............................................

Water recombination .................................................................

Electrocatalysts: their role and functioning.......................................5

Cobalt oxides as oxygen reduction reaction catalysts.........................7

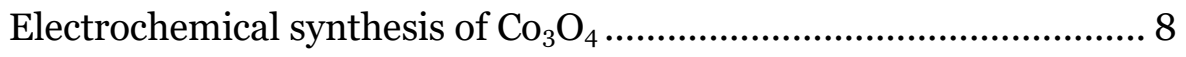

Corrosion of multicomponent materials ................................................ 9

Definition of corrosion and different types of corrosion .................... 9

Passivity and break-down of passive film .......................................... 9

Multicomponent and corrosion resistant materials ..........................10

Thin film growth ................................................................................13

Magnetron sputtering ............................................................... 13

Growth models for thin films........................................................ 14

Physical characterisation techniques................................................ 17

X-Ray Diffraction (XRD) ............................................................. 17

Scanning Electron Microscopy (SEM) ............................................18

Transmission Electron Microscopy (TEM)........................................19

X-Ray Photoelectron Spectroscopy (XPS) .......................................19

Scanning Kelvin Probe Force Microscopy (SKPFM) ....................... 20

Electrochemical methods for analysis of catalysis and corrosion .........21

Electrochemical set-up ...............................................................21

Cyclic voltammetry (CV) and Tafel slopes ................................... 22 
Potentiodynamic (PD) polarisation for corrosion studies ................ 22

Electrochemical Impedance spectroscopy (EIS) ............................. 23

Summary of appended papers ........................................................... 25

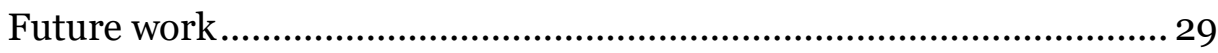

Effect of other elements ....................................................................29

Deposition with HiPIMS ................................................................ 29

Replacing Cobalt ........................................................................... 30

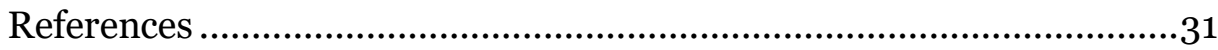




\section{Chapter 1}

\section{Introduction}

Chemical reactions are not just defined by their reactants and products, their kinetics and yield are also of importance. Introducing a catalyst can considerably increase them. Catalysis was first discovered in 1540 by V. Cordus [1], however catalysts were not given their name nor fully understood until the end of 1830s [2]. In electrochemistry they are called electrocatalysts as they help to find an alternative pathway for an electrochemical reaction [3].

An electrochemical reaction of high research interest is ORR, which is one of the two reactions involved in water recombination. In the energy sector different applications are based on water recombination, of which one of the largest today is hydrogen fuel cells [4]. In this thesis the main focus has been on ORR in alkaline electrolytes which can be relevant for alkaline batteries or any electrical process with a water-based electrolyte. Material selection plays a major role in the sustainable development of our modern society along with functionality, but scarcity and thus cost are also important factors. Platinum $(\mathrm{Pt})$ is known as an high-performance catalyst for different applications and is widely used for reduction of oxygen in today's fuel cell applications [5], but its amount needs to be reduced to lower the price of the fuel cell stack for example[4]. Another way to reduce the cost and usage of rare noble metals is to replace Pt with a more abundant element such as Co. Cobalt oxides, in particular, are currently being extensively researched as a possible replacement for $\mathrm{Pt}$ nanoparticles [5].

However, since cobalt oxides are less noble than platinum, they might be more affected by the harsh environment as their chemical resistance is lower. Therefore, their corrosion resistance must be tailored as a complement to their catalytic activities to ensure the durability of the chosen materials. Stainless steels and nickel alloys are widely used in corrosive environments because of their high resistance and stability of their protective passive layers. Passive layers are defined as extremely thin chemical and physical barriers which protects the bulk of the materials and are 
often composed of oxide and hydroxide species. Stainless steels are composed of at least $11 \mathrm{wt} \%$ chromium $(\mathrm{Cr})$, which enables them to form a protective chromium oxide layer [6].

Steel alloys classify as one major element alloys because they are mainly composed of iron $(\mathrm{Fe})$. In the alloy classification a new category of alloys has been introduced, called high entropy alloys (HEA). These new alloys are multi-component alloys, where several elements are present in equimolar or near-equimolar ratios, which increases their entropy of mixing, and thus called high entropy alloys [7]. One of the emerging alloys is $\mathrm{CoCrFeMnNi}$, also known as the Cantor alloy as it was first reported by Cantor et al. [8]. The single-phase structure and increased mechanical properties compared to one major element alloys has brought much interest for these new material systems. Some of that interest is directed towards corrosion properties and show promising results for various applications, such as sea water and marine applications, strong acids or even alkaline environments. In most cases, the high corrosion resistance is attributed to the strength of the $\mathrm{Cr}$ oxide, but also to the lack of phase segregations which inhibit micro-galvanic corrosion.

In this thesis, catalytic activity and corrosion resistance are combined into one material system synthesised as a thin film, to benefit from the versatility of coating techniques. $\mathrm{CoCrFeNi}$, in this fast-growing materials research field, has a high potential for fulfilling the two main research goals of this thesis: a material system with catalytic activity, here achieved by $\mathrm{Co}$, combined with a high corrosion resistance, ensured by $\mathrm{CrFeNi}$.

\section{Aims of thesis}

The aims of the thesis are the following:

- Investigate electrochemically modified Co thin films and understand how they are active towards ORR

- Investigate the structure and the corrosion resistance of multicomponent thin films $\mathrm{CoCrFeNi}$, and the influence of a Fe composition gradient on the film properties 
- Gain insight on how catalytic properties can be combined with corrosion resistance

The following chapters are dedicated to explaining in further details the concepts involved in this research work and then to present and discuss the results of the study of cobalt based thin films, their catalytic activity, and their corrosion resistance. 
Chapter 2

\section{Electrocatalysis of the reduction of oxygen}

\section{Water recombination}

Water recombination, as it names indicates, is the recombination of oxygen $\left(\mathrm{O}_{2}\right)$ and hydrogen $\left(\mathrm{H}_{2}\right)$ gases to form water. This reaction is found in energy applications, for example in fuel cells where hydrogen fuel and oxygen in the air are combined.

The main reaction for water recombination can be written as:

$$
\mathrm{O}_{2}+2 \mathrm{H}_{2} \rightarrow 2 \mathrm{H}_{2} \mathrm{O}
$$

It can be divided into two half-cell redox reactions (written here in alkaline environment):

○ Oxygen Reduction Reaction (ORR)

$$
\mathrm{O}_{2}+2 \mathrm{H}_{2} \mathrm{O}+4 e^{-} \rightarrow 4 \mathrm{OH}^{-}
$$

- Hydrogen Oxidation Reaction (HOR)

$$
\mathrm{H}_{2}+2 \mathrm{OH}^{-} \rightarrow 2 \mathrm{H}_{2} \mathrm{O}+2 e^{-}
$$

ORR is the kinetically limiting half reaction in the water recombination reaction because of the need for breakage of the oxygen-oxygen bond, one of the strongest chemical bonds, and the transfer of four electrons. Therefore, there is a need to introduce a catalyst at the ORR electrode to make the process efficient.

\section{Electrocatalysts: their role and functioning}

Electrocatalysis refers to the catalysis of an electrochemical reaction where the electrocatalyst usually works as an electrode. Similarly to catalysts, its role is to reduce the energy barriers (Figure 1) and increase the kinetics of a reaction [3]. In the case of ORR, the catalysis is classified as heterogenous: the catalyst and reactant are in different physical states. 
The effect of the catalyst can be seen as lowering the overpotential (potential difference between theoretical and experimental value) and increasing the current density (rate of electron transfer) [9].

ORR can be divided into three different steps: 1) Adsorption of oxygen molecules onto the catalyst surface and transfer of electrons, 2) breakage of oxygen-oxygen bonds and protonation, 3 ) release of hydroxide ions $[10,11]$.



Figure 1: Schematic representation of activation energy reduced by catalyst and ORR reaction taking place on surface of a catalyst.

Until this point only the reaction with a four-electron transfer has been discussed and is called direct pathway for the reaction. There is also an undirect pathway which involves an intermediate step with the formation of hydrogen peroxide anion and transfer of two electrons [12]. The peroxide anion is then further oxidised with a second two-electron transfer and forms the hydroxide ions. For ORR catalysts both pathways have been reported. 


\section{Cobalt oxides as oxygen reduction reaction catalysts}

In the following section catalyst candidates for ORR and its reversed reaction oxygen evolution reaction (OER) are reviewed $[13,14]$.

$\mathrm{Pt}$ and palladium $(\mathrm{Pd})$ have been reported as excellent catalyst candidates with high activity for ORR $[10,14]$, but because of their cost and scarcity there is a need for replacing these precious metals. Therefore $3 \mathrm{~d}$ transition metals oxide catalysts have been extensively studied and reported in different reviews $[10,15,16]$.

Among the reviewed candidates, cobalt oxide $\mathrm{Co}_{3} \mathrm{O}_{4}$ stands out for its good properties such as low electrical resistance and high electron transfer kinetics $[17,18] . \mathrm{Co}_{3} \mathrm{O}_{4}$ has a spinel structure, meaning $\mathrm{Co}^{2+}$ and $\mathrm{Co}^{3+}$ cations are placed in interstitial sites of a face centred cubic (FCC) $\mathrm{O}^{2-}$ structure (Figure 2).

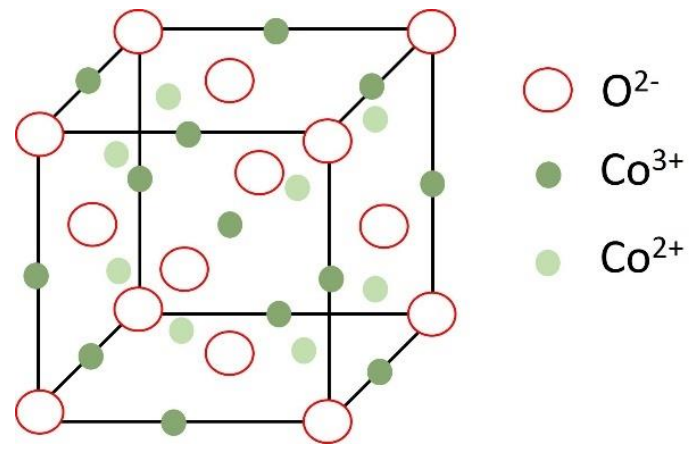

Figure 2: Schematic representation of the spinel structure of $\mathrm{CO}_{3} \mathrm{O}_{4}$. $\mathrm{CO}^{3+}$ and $\mathrm{CO}^{2+}$ in interstitial sites of an $\mathrm{FCC} \mathrm{O} \mathrm{O}^{2}$-lattice.

Co cations allow adsorption/desorption mechanisms and electron transfer in the spinel suitable for ORR and OER reactions [10,19]. Furthermore, $\mathrm{Co}_{3} \mathrm{O}_{4}$ is stable at high $\mathrm{pH}$ and therefore applicable to alkaline processes [20]. The synthesis of $\mathrm{Co}_{3} \mathrm{O}_{4}$ can be carried out in several ways: from Co hydroxides with other precursors in different solutions to the oxide structure by annealing, or by electrochemical processes [9]. Tailoring the morphology of the spinel leads to higher surface area and thus more active sites and catalytic activity [16]. Liang et al. [9] synthesized $\mathrm{Co}_{3} \mathrm{O}_{4}$ nanoparticles on graphene sheets and found excellent ORR and OER activity 
in basic environment. After this study in 2011, $\mathrm{Co}_{3} \mathrm{O}_{4}$ had become more and more investigated as nanoparticles anchored to graphene sheets [11], $\mathrm{Co}_{3} \mathrm{O}_{4}-\mathrm{N}-\mathrm{C}$ nanocomposites [19], nanochains [14] and nanorods [21].

\section{Electrochemical synthesis of $\mathrm{Co}_{3} \mathrm{O}_{4}$}

In this thesis, electrochemically modified thin films have been investigated based on processes for metallic Co. According to the study of Cassir et al. [20] on the Pourbaix diagrams of cobalt, $\mathrm{Co}_{3} \mathrm{O}_{4}$ is the stable phase at high $\mathrm{pH}$ and could theoretically be formed when a potential is applied, which was further experimentally demonstrated by both Strehblow et al. [22] and Gallant et al. [23] by the formation of $\mathrm{a} \mathrm{Co}_{3} \mathrm{O}_{4}$ layer on top of Co rods. The application of potential can also alter the morphology of cobalt oxide particles as it has been reported by Mathankumar et al. [24].

To summarise, the reduction of oxygen is part of the water recombination process and because of its slow kinetics it requires an electrocatalyst to increase the rate of the reaction. Catalysts provide an alternative pathway by adsorption of oxygen and electron transfer through their active sites. Such catalysts can either be noble metals, Pt or Pd, or more recently investigated spinel cobalt oxides.

Catalyst synthesis can be carried out with different methods used for example to fabricate nanoparticles, and in this thesis thin films. 
Chapter 3

\section{Corrosion of multicomponent materials}

\section{Definition of corrosion and different types of corrosion}

Corrosion is the general term for material break-down due to chemical and/or electrochemical processes. For metallic materials, an oxidation and a reduction reaction usually take place on the surface exposed to the corrosive environment $[6,25]$. How these reactions occur is what defines the different types of corrosion, namely uniform corrosion, localised or selective corrosion [25].

Uniform corrosion is defined as a homogeneous attack over the whole surface, whereas localised and selective corrosion take place at smaller specific areas of the surface [26,27]. Initiation points for localised corrosion could for example be variations in the microstructure, presence of impurities and defects. In all cases the microstructure and composition of the material play a role because they are interlinked with the chemical resistance of the material.

\section{Passivity and break-down of passive film}

Certain metallic materials have the ability to form a thin protective layer on their surfaces which will act as a physical and chemical barrier against the corrosive environment [25,28-30]. This process is known as passivity or the formation of a passive layer. The layer is mostly composed of metal oxides and hydroxides as the results of instantaneous oxidation of surfaces when in contact with air for example.

However, the passive film is not invincible and can be broken down by corrosive species. Anions in the electrolyte, such as chlorides, can attack the passive film and damage it. Underneath the damaged passive film the bulk material is no longer protected and will start to corrode, uninterruptedly in cases of pitting corrosion [31].

Figure 3 schematically represents the corrosion mechanism of pitting corrosion after localised break-down of the passive film. In some cases, the 
pits get covered with metal oxides and hydroxides, making the corrosion attacks even harder to detect which can have disastrous consequences on structural components.

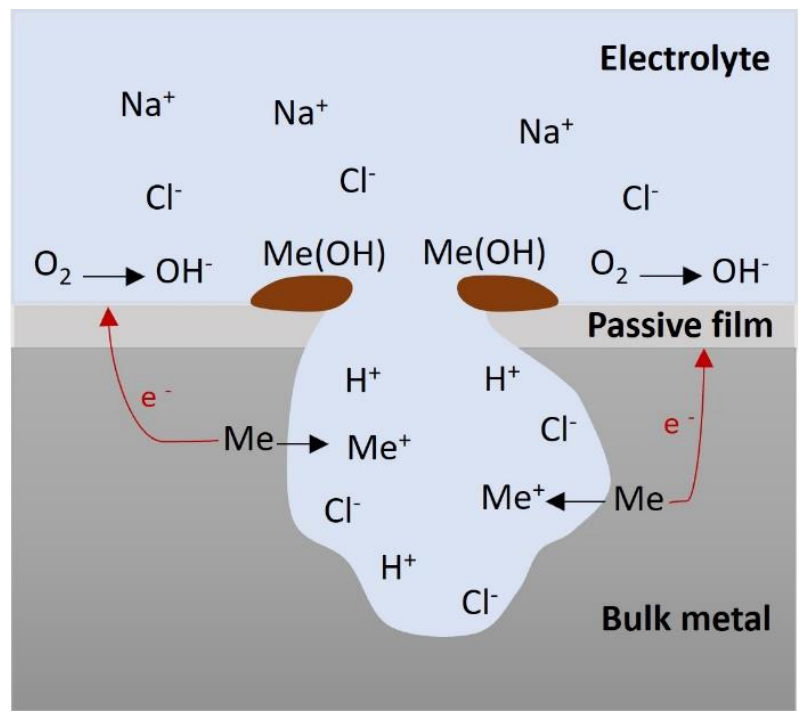

Figure 3: Schematic representation of localised corrosion after breakdown of the passive film.

To investigate the corrosion resistance and mechanism of different materials, electrochemical methods are powerful tools for this purpose. The methods employed in this thesis are described in Chapter 6.

\section{Multicomponent and corrosion resistant materials}

The materials which have been in the centre of this thesis work are multicomponent materials, otherwise known as high entropy alloys (HEA). HEA were first discovered by Yeh et al. [7] and Cantor et al. [8] in 2004 and are based on multiple principal element alloys where five or more elements are present in equimolar or nearly equimolar proportions. The alloys tend to form single-phase microstructures because of their entropy of mixing and thus lowered Gibbs energy [32], and this affects their physical properties. A typical example of this is the enhancement of mechanical properties compared to those for one major element alloys e.g., steel 
or nickel alloys [33-35]. Another interesting property is enhanced corrosion properties due to phase stability and to high concentration of passivating elements such as $\mathrm{Cr}$.

The following sections describe the corrosion studies, of the alloys and thin films, which inspired the material selection for this thesis.

There are three main corrosive environments which have been investigated for HEAs: acidic with $\mathrm{H}_{2} \mathrm{SO}_{4}$ or $\mathrm{HCl}$, neutral chloride environments, mainly $\mathrm{NaCl}$, and finally alkaline environments with $\mathrm{NaOH}$ or $\mathrm{KOH}$. Results from acidic and neutral environments can be useful to learn about the alloys when subjected to general corrosion (acidic) or localised corrosion (acidic and neutral). These types of corrosion are observed to a lower extent in alkaline environment, which is typical for the applications targeted in this thesis.

\section{Multicomponent alloys}

In this section, the corrosion properties of bulk alloys will be discussed at first, as the number of research studies for them is considerably higher than coatings and thin films. Hsu et al. [36] were one of the first research groups to investigate the corrosion behaviour of $\mathrm{CoCrFeNi}$. They found that the alloy had a similar behaviour to stainless steel in $\mathrm{NaCl}$ and that the addition of $\mathrm{Cu}$ to the alloy was detrimental due to formation of segregated $\mathrm{Cu}$-rich areas, with a lower corrosion resistance. $\mathrm{CoCrFeNi}$ have been extensively studied since then [37-40], and the addition of other elements such as $\mathrm{Al}[32,37,38,41-43], \mathrm{Mn}$ [44] and $\mathrm{Cu}$ [32] have been reported. Results from these studies consistently show that $\mathrm{CoCrFeNi}$ has a high corrosion resistance, similar to stainless steels $304 \mathrm{~L}$ and 316L, attributed to the formation of a protective $\mathrm{Cr}$ rich passive film. However, in $\mathrm{NaOH}, \mathrm{Cr}$ can be dissolved which lowers the corrosion resistance [39].

\section{Multicomponent coatings and thin films}

$\mathrm{CoCrFeNi}$ variants have extensively been synthesised by magnetron sputtering [45-49]. The focus of the sputtered film studies has, however, not always been corrosion properties. Results for magnetron sputtered 
AlCoCrFeNi can be found in studies by Gao et al. [50] and Shi et al. [51]. Both of them conclude that $\mathrm{Al}$ has a negative effect on the corrosion properties. $\mathrm{CoCrFeNi}$ and $\mathrm{CoCrCuFeNi}$ films synthesised by vacuum hot sintering [52], CoCrFeMnNi by laser cladding [53] and by electrodeposition [54], and CoCrFeNbNi by plasma spraying [55] effectively protected the substrates and showed similar corrosion resistance to stainless steel 304L in $\mathrm{NaCl}$ and in $\mathrm{H}_{2} \mathrm{SO}_{4}$. CoCrFeMnNi was more sensitive to pitting corrosion in $\mathrm{NaCl}$ and over time the resistance of the passive film was decreasing due to the corrosion of $\mathrm{Cr}$ depleted dendrites in $\mathrm{H}_{2} \mathrm{SO}_{4}$ [53].

To summarise, corrosion is an electrochemical process which leads to material degradation, that can be prevented by the formation of a thin protective oxide layer. The CoCrFeNi system belongs to a multicomponent family called High Entropy Alloys (HEA). The structural benefits of the alloy itself and the additions of other elements have been reported. The reported results show promising corrosion properties, suitable for the scope of this thesis. 


\section{Chapter 4}

\section{Thin film growth}

\section{Magnetron sputtering}

Magnetron sputtering is a physical vapor deposition (PVD) technique, widely used for deposition of thin films. Targets with the desired coating materials are placed in a vacuum chamber along with the substrate. By introducing an inert gas such as Ar, ionising it by means of an electric field and accelerating it towards the target, atoms from the target material can be sputtered into a plasma. The atoms in the plasma can then condensate onto the substrate and grow a film. Figure 4 schematically represents the sputtering system used for the work in this thesis.

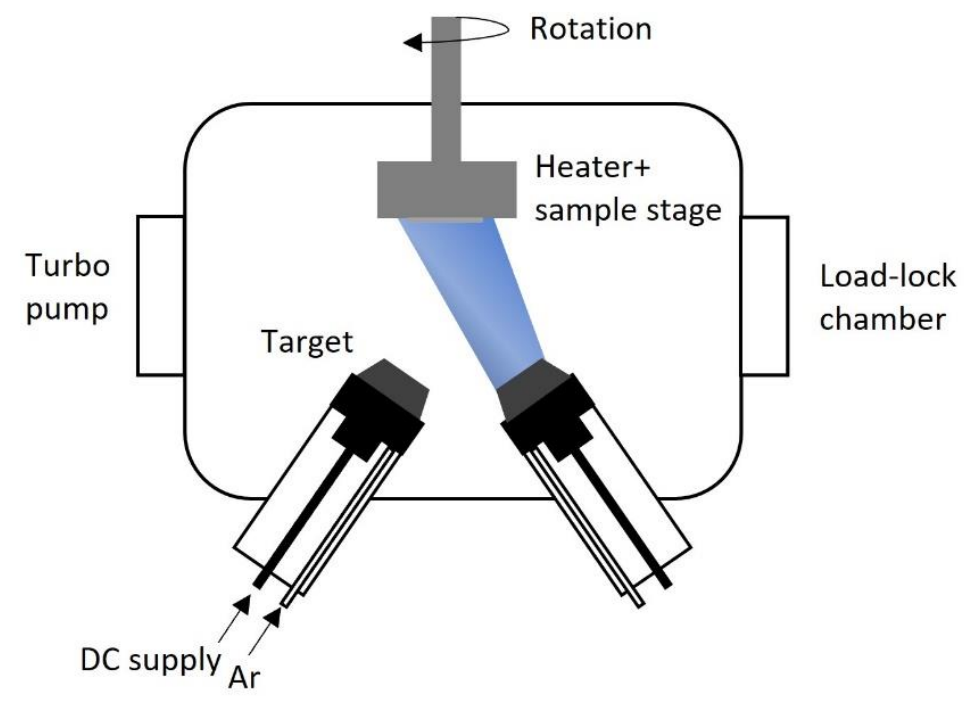

Figure 4: Schematic representation of the magnetron sputtering system used for the film depositions.

The targets can be elemental targets or compound alloy targets [56-58] and usually two or more targets are used for co-deposition [57], which allows versatility of the thin film composition. 
The strength of the electric and magnetic field can be controlled by the applied power to each target, this will impact the sputter yield. Other deposition parameters such as target-substrate distance, substrate electrical bias and substrate temperature [59] can alter the growth of the film in terms of film density and crystal orientation for example.

\section{Growth models for thin films}

At the initial steps of the thin film deposition process, several atoms from the plasma will condensate on the substrate and form nuclei, then clusters, followed by a first monolayer. The morphology of the film is interlinked to the formation of these first layers of atoms as new layers will grow on top of them [60]. Altering the formation of these initial layers can be done by several means, the most common ones are based on how to increase or decrease surface diffusion of adatoms. Increasing the substrate temperature usually increases the surface diffusion of adatoms and they can form larger clusters which results into larger grains, for $\mathrm{CoCrFeNi}$ commonly from $50 \mathrm{~nm}$ to $100 \mathrm{~nm}$ in width $[45,61,62]$.

Crystal orientation and texture also influences the morphology. As atom layers form, the surface diffusion determines at which positions atoms bond together [63]. Several orientations can be present at the early stages of growth (Figure 5) until the kinetics of one orientation dominates the others and continues to grow within the column. This process is usually referred as competitive growth [64,65]. In the case of CoCrFeNi, competitive growth has been reported for FCC structures with (111) main orientation $[45,47]$.

The different growth trends and resulting morphologies have been summarised into structure zone models (SZM) first established by P.B. Barna and M. Adamik in 1998 [64]. SZM are defined according to the substrate temperature $T_{S}$ over the melting point $T_{m}$ ratio. Three different zones have been identified: zone I where $\mathrm{T}_{\mathrm{s}}<<\mathrm{T}_{\mathrm{m}}$ and the formation of narrow grains due to low diffusion, zone II where $\mathrm{T}_{\mathrm{s}}$ and $\mathrm{T}_{\mathrm{m}}$ are closer to each other and large grains can form; and an intermediate zone, zone $\mathrm{T}$ in between 1 and 2 where $T_{s}<T_{m}$ and competitive growth can occur. 


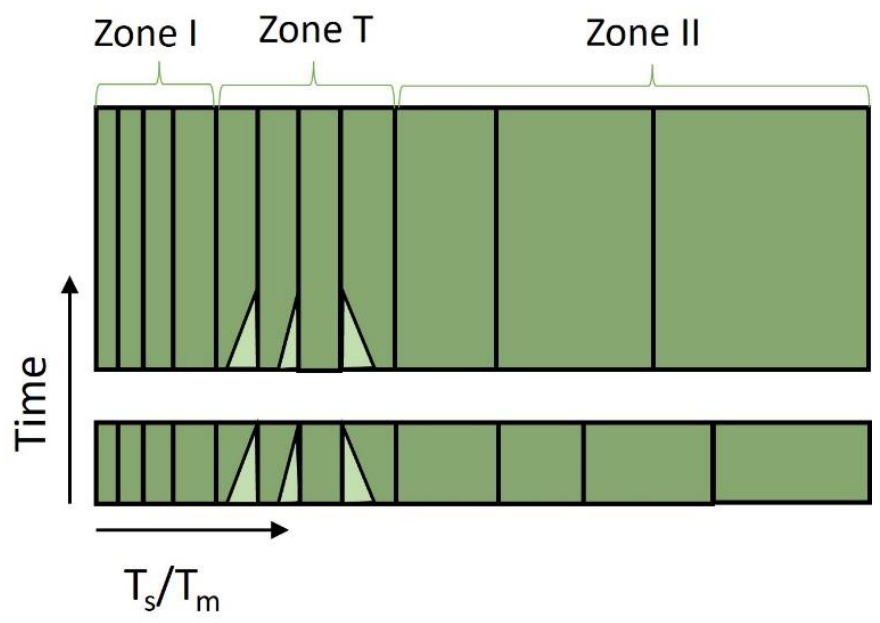

Figure 5: Schematic representation of structure zone models. The light shaded areas represent crystals with a different orientation from the main texture orientation.

For CoCrFeNi thin films, columnar growth is recurrent in literature [45$48,61,62,66]$, and some have identified zone $\mathrm{T}$ at low temperatures $\left(\mathrm{T}<500^{\circ} \mathrm{C}\right)[45,47]$ and zone II for higher temperatures $\left(\mathrm{T}=900^{\circ} \mathrm{C}\right)[45]$.

To summarise, thin films can be deposited with magnetron sputtering, a PVD technique, where atoms from a target material are sputtered away into a plasma by accelerated ionised Ar gas. The atoms condensate on a substrate and start to grow a film. The growth and morphology of the films can be altered by changing deposition parameters, e.g substrate temperature which affects the adatom diffusion. 
Chapter 5

\section{Physical characterisation techniques}

Several characterisation techniques have been utilised for this thesis work to gain information about the crystal structure, thin film morphology, chemical state and bonds on the surface of the material.

\section{X-Ray Diffraction (XRD)}

X-rays were first discovered by W. Röntgen in 1895 [67] and are still today used for medical application and for material characterisation. The wavelength of x-rays emitted by a metallic anode is very close to the atomic spacing within a crystalline material [68]. Therefore, the $\mathrm{x}$-rays can be diffracted in different pattern, depending on the crystal orientation. By measuring the interference pattern together with Bragg's law, the atomic spacing can be determined (Figure 6). Bragg's law is described as $2 \mathrm{~d} \sin (\theta)=\mathrm{n} \lambda$, where $\mathrm{d}$ is the atomic spacing, $\theta$ the angle of the reflected beam, $\mathrm{n}$ the order of diffraction and $\lambda$ the $\mathrm{x}$-ray wavelength.

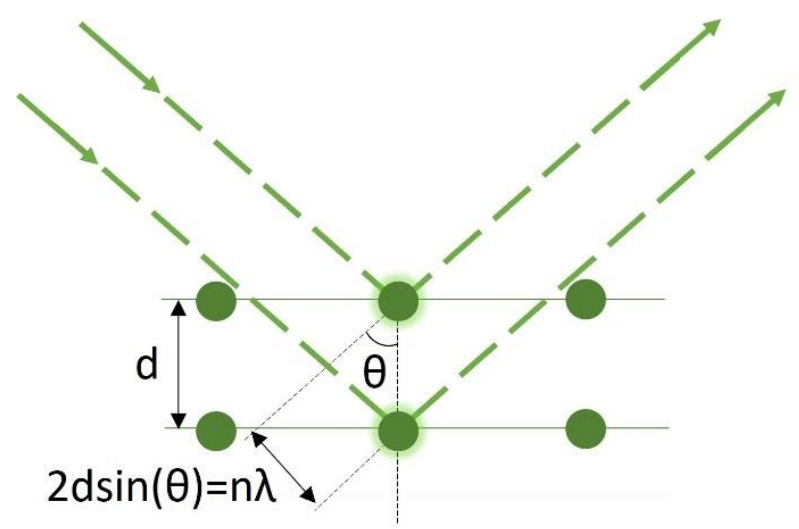

Figure 6: Schematic of x-rays diffraction and application of Bragg's law. 


\section{Scanning Electron Microscopy (SEM)}

Scanning electron microscopy, first made available by M. von Ardenne in 1937 [69], is a powerful tool to study microstructure, morphology and chemical composition of a material. A high voltage (1-20 kV) focused electron beam is used as an energy source to bombard the surface of the studied material and their interaction can be detected. The type of information depends on which emitted electrons or x-rays that are analysed. The different interaction levels are schematically represented in Figure 7.

\section{Electron beam}

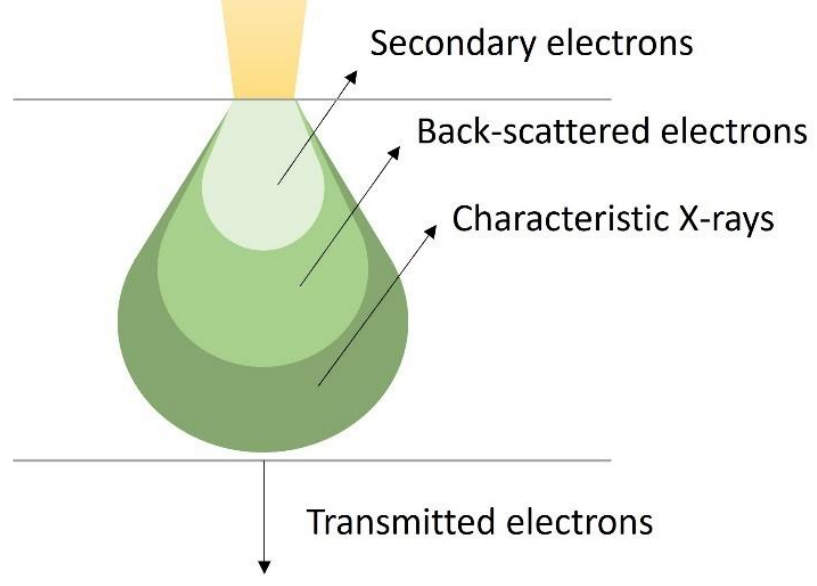

Figure 7: Schematic representation of the interaction volume in electron microscopy and the emitted species.

Secondary electrons are valence electrons ejected from the sample after interaction with the electron beam. These electrons are detected with a secondary electron emission detector and are used to create images of the samples. Elastically scattered electrons are known as back-scattered electrons and can also be used to create images with higher elemental contrast; however, this type of imaging was not used in this thesis. The elemental characterisation was caried out with Energy Dispersive Spectroscopy (EDS) instead. This technique is based on the $\mathrm{x}$-rays generated from the sample after interaction with the electron beam. 


\section{Transmission Electron Microscopy (TEM)}

In electron microscopy when the beam is transmitted through the sample, the mode is called Transmission Electron Microscopy (TEM). After preparation of a thin lamella ( $<100 \mathrm{~nm}$ in thickness) with Focused Ion Beam (FIB), advanced microstructural observations on the atomic scale are possible. These observations include not only imaging and chemical analysis, but also crystallography by means of diffraction when using selected area electron diffraction (SAED). This technique was used for analysis of passive films and detailed observation of the thin film structure in Paper 2.

\section{X-Ray Photoelectron Spectroscopy (XPS)}

$\mathrm{X}$-rays and their interaction with matter can also be used to determine different type of bindings within a material. X-Ray Photoelectron Spectroscopy (XPS) was first introduced by K. Siegbahn in 1954 [70] and uses the photoelectric principle introduced by H. Hertz in 1887 [71]. During an XPS measurement, the sample is irradiated with X-rays and their interaction will produce photoelectrons. The binding energy $\mathrm{E}_{\mathrm{b}}$ is then calculated from A. Einstein's photoelectric law: $E_{k}=h v-E_{b}-\varphi$, where $E_{k}$ is the kinetic energy, hv is the energy of the $\mathrm{x}$-rays and $\varphi$ the work function of the spectrometer.

Each element has a specific binding energy range on the photoelectron spectrum. Furthermore, the different chemical bonds for each element can be differentiated in the spectrum, therefore this technique is powerful when characterising the chemical species of a material. Moreover, the technique is extremely surface sensitive which allows the analysis of only the first few nanometres of a material.

In paper 1, XPS was used to confirm the spinel structure of $\mathrm{Co}_{3} \mathrm{O}_{4}$ and also to follow the oxidation state of the electrocatalyst after ORR testing. 


\section{Scanning Kelvin Probe Force Microscopy (SKPFM)}

SKPFM is an atomic force microscopy (AFM) based technique which enables the measurement of topography and electric potential of a surface with nanometre resolution. A conductive AFM probe scans the surface of a material and interacts with it due to atomic forces and topography. This will move the tip in and out of plane and the movements of the tip are followed by a laser and a detector, schematically represented in Figure 8. In SKPFM, the electric potential differences over the surface are also measured by the tip to generate Volta potential maps.

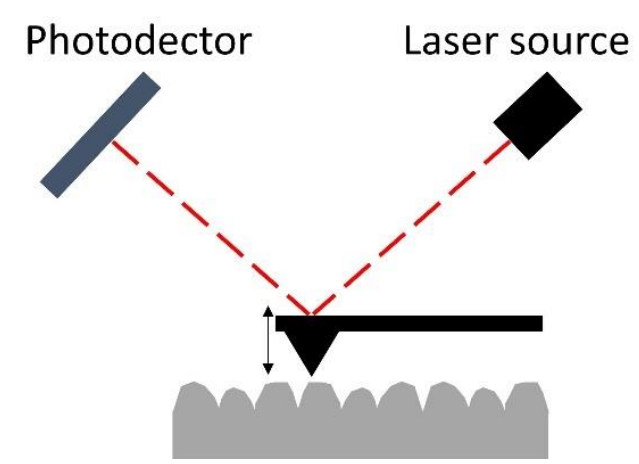

Figure 8: Schematic representation of AFM probe used for SKPFM measurements.

The potential differences are directly related to the material properties, in particular the energy required to remove electrons from the surface, known as the Fermi level and the electrochemical potential [72]. This was used in Paper 2 to understand the corrosion properties of the films. Indeed, potential maps can identify anodic and cathodic regions and predict where a corrosion process might initiate. Anodic regions have a lower potential than cathodic regions and are therefore more likely to be selectively oxidised in a corrosive environment. 
Chapter 6

\section{Electrochemical methods for analysis of catalysis and corrosion}

\section{Electrochemical set-up}

A 3-electrode set-up has three electrodes: the working electrode, which is the studied material, a reference electrode with a constant potential value and a counter electrode to close the circuit. Usually, a potential, measured against the reference electrode, is applied between the working and counter electrode. This disturbs the studied material away from its equilibrium and generates a current which is measured. In this thesis an Avesta cell has been used, represented schematically in Figure 9.

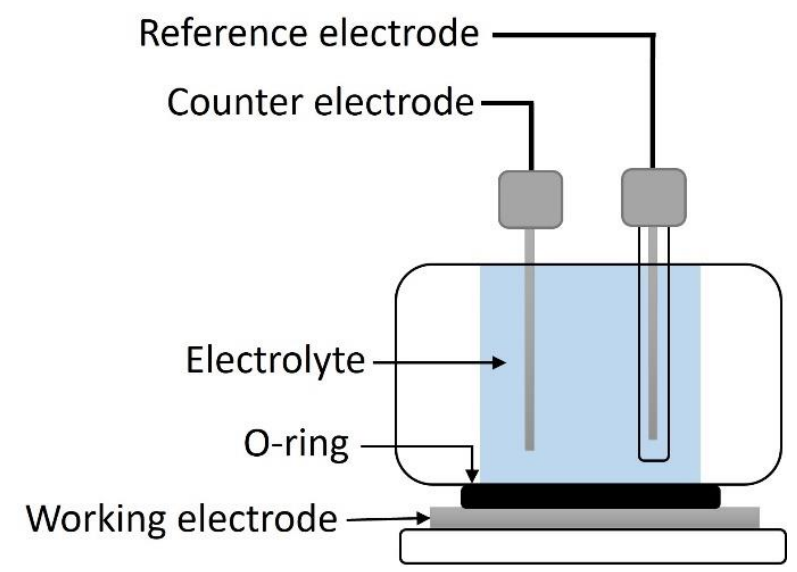

Figure 9: Schematic representation of a 3-electrode Avesta cell.

An Avesta cell is considered as a 3-electrode cell with the additional advantage of having a low flow of deionised water around the O-ring to avoid formation of crevices which can influence the corrosion mechanism during the measurements. 


\section{Cyclic voltammetry (CV) and Tafel slopes}

The principle of cyclic voltammetry $(\mathrm{CV})$ is to scan a voltage range at a certain scan rate and measure the current response. Current peaks at certain potentials give the equilibrium potentials $\mathrm{E}^{0}$, also called Nernst potentials, which correspond to redox reactions. Kinetic constants can also be determined by $\mathrm{CV}$ and even more specifically with Tafel plots. Usually, these plots are defined in function of the overpotential $\eta$, which is the potential difference required for the system to reach the equilibrium state. A common way to compare the performances of different materials is to use their Tafel slopes extracted from these plots. For example, the higher the slope value the slower the kinetics of the reaction are. One can even go further in the analysis and extract the exchange current density, which gives information about the catalyst when no overpotential is applied, and the kinetic rate constant for estimating the rate of the reaction.

\section{Potentiodynamic (PD) polarisation for corrosion studies}

$\mathrm{CV}$ can also be used for corrosion studies but is then more commonly known as potentiodynamic (PD) polarisation. Using the same principle as a classical $\mathrm{CV}$, a potential is applied and scanned in a given range and rate while the current response is recorded. Before recording a PD curve, it is common to measure the free corrosion potential, or open circuit potential (OCP). This gives an indication on the equilibrium potential at the start of the corrosion process. A PD curve is usually recorded $250 \mathrm{mV}$ below the OCP to be able to observe the initiation of corrosion. From the $\mathrm{PD}$ measurements corrosion parameters such as corrosion potential $\mathrm{E}_{\text {corr }}$, corrosion current density $j_{\text {corr, }}$ passive current $j_{\text {pass }}$ and transpassive potential $\mathrm{E}_{\text {crit }}$ can be extracted. A schematic representation of these parameters is shown in Figure 10. 


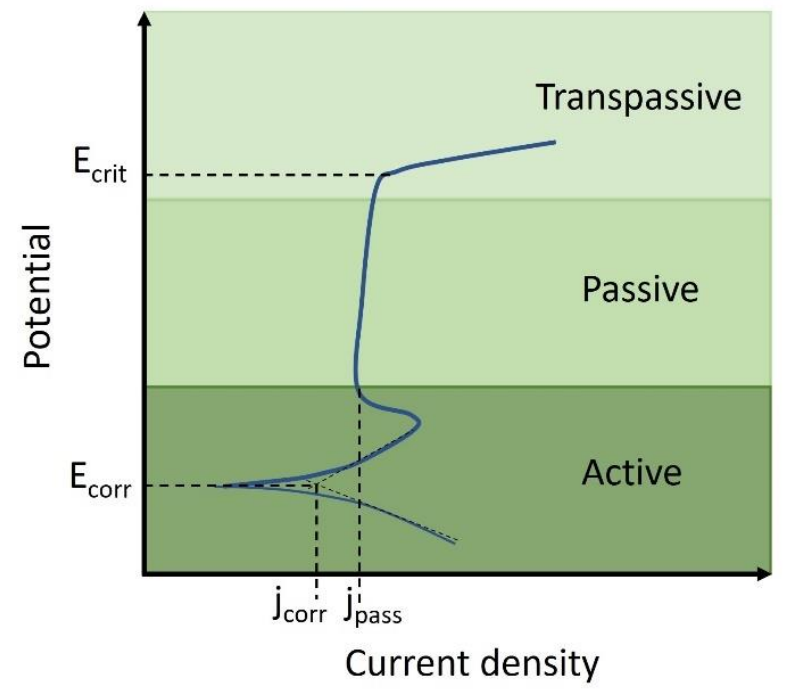

Figure 10: Schematic representation of a potentiodynamic polarisation curve and the different corrosion parameters.

The corrosion current density, $\mathrm{j}_{\text {corr }}$ is extracted through Tafel extrapolation around $\mathrm{E}_{\text {corr }}$ where Tafel slopes are used, and $\mathrm{j}_{\text {corr }}$ is found at their interception. The current corresponds to the flow of electrons on the surface when the material starts to oxidise and is thus inversely related to the corrosion resistance of the material. Once the surface has oxidised it can either continue to be oxidised and is then active, or it can form a protective layer which interrupts the corrosion and it therefore called passive region with a constant current density, jpass. Once this protective layer breaks down, active corrosion takes place again at $\mathrm{E}_{\text {crit }}$ and the current density increases rapidly in the transpassive region.

\section{Electrochemical Impedance Spectroscopy (EIS)}

EIS is a series of techniques which can be used to investigate surfaces. An alternating potential is applied to the electrochemical cell with varying frequencies and the current response is measured. The obtained data can be fitted to an impedance value for an equivalent electronic system with components such as capacitors and resistors to model the reactions 
taking place. One of the most common circuits is the Randles circuit, which consists of two resistors and one capacitor (Figure 11).

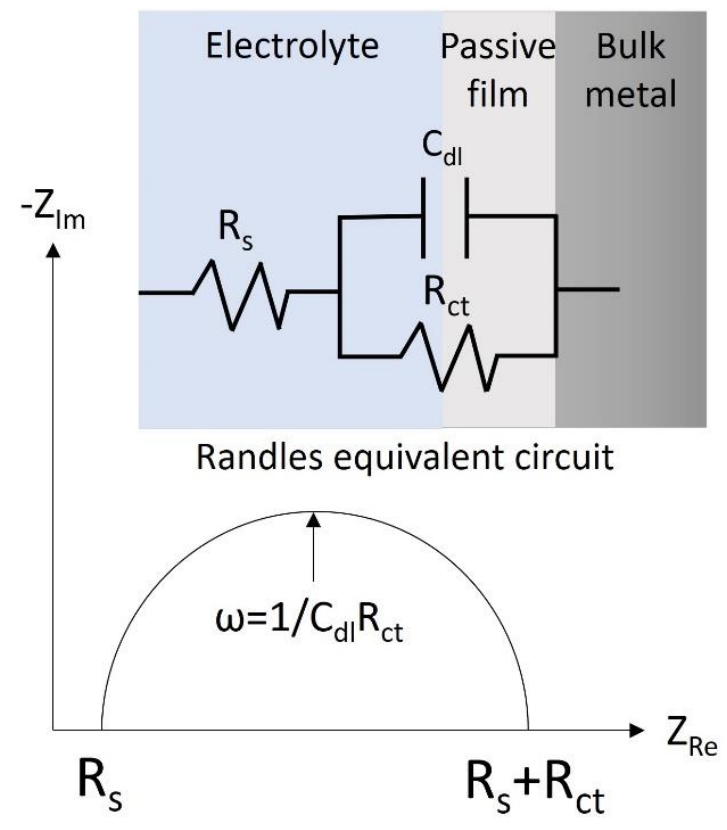

Figure 11: Schematic representation of Nyquist plots and EIS data simulated with a Randles equivalent circuit.

The first resistor $R_{s}$ is attributed to the resistance of the electrolyte. The second one is related to the resistance of the studied material, usually defined as a charge transfer resistance $R_{c t}$ and it corresponds specifically to the resistance of the passive film in corrosion studies. The third component is a capacitor to model the double layer formed at the material-electrolyte interface and its capacitance, $\mathrm{C}_{\mathrm{dl}}$ is resulting from charge compensation. From the Nyquist plot and known angular frequency $\omega$ the values for $\mathrm{R}_{\mathrm{s}}, \mathrm{R}_{\mathrm{ct}}$ and $\mathrm{C}_{\mathrm{dl}}$ can be extracted and used to compare different materials with one another.

Other components can be added such as constant phase elements when the capacitors are not considered as ideal, or more circuits can be added in series or parallel when several processes are involved on the surface of the samples. 


\section{Chapter 7}

\section{Summary of appended papers}

In Paper 1, Co thin films were deposited on steel substrates, using magnetron sputtering, and then electrochemically modified to produce active sites for catalysis. The electrochemical process used was an anodization where a potential step was applied to first remove the passive layer and then re-oxidise the surface, in this case grow cobalt oxide, $\mathrm{Co}_{3} \mathrm{O}_{4}$, hexagonal particles (Figure 12).
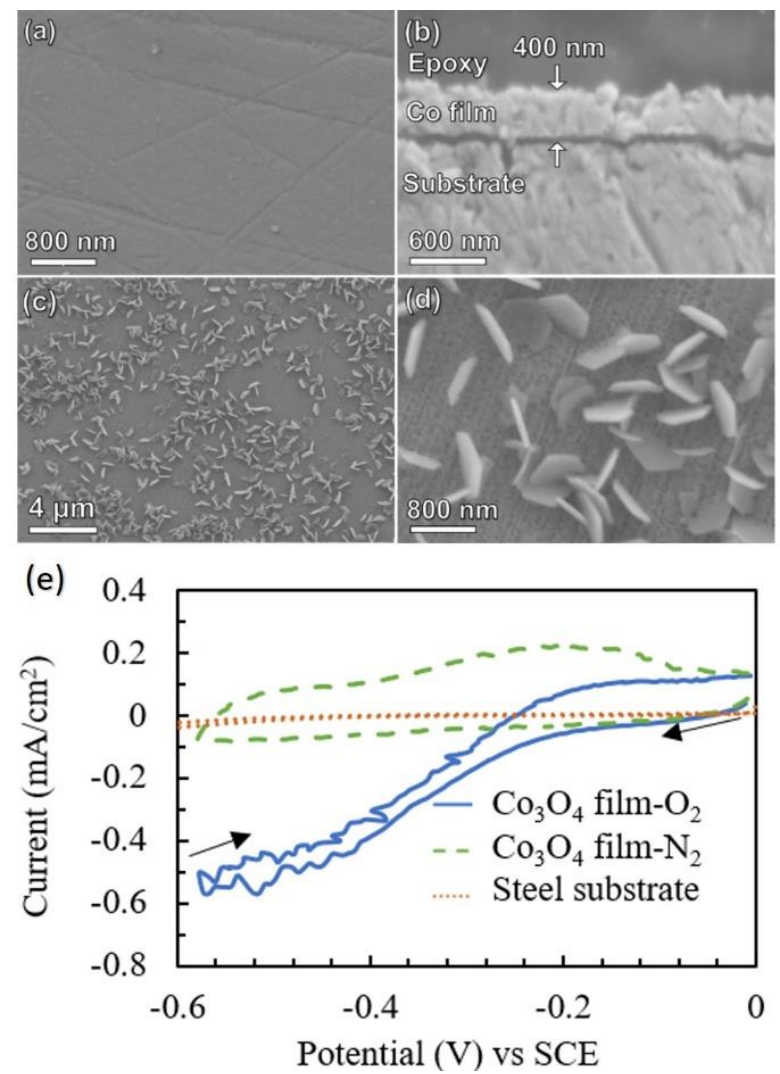

Figure 12: SEM images of the surface (a) and cross-section (b) of the Co thin film as deposited; (c-d) of the anodized film with $\mathrm{Co}_{3} \mathrm{O}_{4}$ particles; (e) $\mathrm{CVs}$ for anodized $\mathrm{Co}$ film in oxygen rich solution $\left(\mathrm{Co}_{3} \mathrm{O}_{4}\right.$ film- $\left.\mathrm{O}_{2}\right)$, oxygen free solution $\left(\mathrm{Co}_{3} \mathrm{O}_{4}\right.$ film- $\left.\mathrm{N}_{2}\right)$ and for substrate in oxygen rich solution (Steel substrate). 
Once the thin films were anodized, the performance towards ORR was investigated in $\mathrm{O}_{2}$ saturated $1 \mathrm{M} \mathrm{KOH}$. The current densities recorded by CVs were up to $0.7 \mathrm{~mA} / \mathrm{cm}^{2}$ and $0.35 \mathrm{~mA} / \mathrm{cm}^{2}$ for chronoamperometry. The current response was rapid and stable in both cases. The presence of $\mathrm{Co}^{3+}$ ions is assumed to be the key reason for the catalytic activity, based on previous studies in literature.

After catalysis testing, the films were analysed once more and evidence of further oxidation was observed, which indicated that the films were oxidised during the testing which could be detrimental for the long-term performances.

Nevertheless, thin film deposition was proven to be a way of functionalising surfaces, the oxide film clearly increased the catalytic activity compared to the bare steel substrate, which is promising for the research on water recombination.

In Paper 2, the multicomponent system $\mathrm{CoCrFe}_{\mathrm{x}} \mathrm{Ni}$ was synthesised as thin films and studied in terms of structure, corrosion properties and catalytic activity. The effect of Fe was investigated by introducing a composition gradient in the $\mathrm{CoCrFe}_{\mathrm{x}} \mathrm{Ni}(0.0 \leq \mathrm{x} \leq 0.7)$ films.

From XRD measurements, it was observed that the Fe content influences the crystal structure of the films. With a Fe content higher than $\mathrm{x}=0.3$, the films have a single FCC phase. Below that content, the films presented a hexagonal close packed (HCP) phase in addition to the FCC. In TEM analysis, the structure was confirmed by SAED, and for $\mathrm{x}=0.7$ higher amount of stacking faults defects was observed compared to $\mathrm{Fe}$ free films.

The corrosion resistance of the films was investigated in two environments $0.1 \mathrm{M} \mathrm{NaCl}$ and $1 \mathrm{M} \mathrm{KOH}$. In NaCl, the films with high Fe content $(\mathrm{x}=0.7)$ had the highest corrosion resistance. The high resistance was attributed to less defined columnar grains and higher defect density which led to the formation of a more protective passive film. In $\mathrm{KOH}$ the medium $\mathrm{Fe}$ content $(\mathrm{x}=0.3)$ presented the lowest corrosion current density and higher resistance of the passive layer. The higher performances were 
related to the lower Fe dissolution rate into the electrolyte and the buildup of a thick and protective hydroxide layer. In SKPFM measurements (Figure 13 a) a volta potential difference between the top of the grains and grain boundaries was measured for the as-deposited films. After exposure to $\mathrm{KOH}$ the differences were less obvious for $\mathrm{CoCrFe}{ }_{0.0} \mathrm{Ni}$, which indicates even oxidation and the formation of a homogenous passive film.
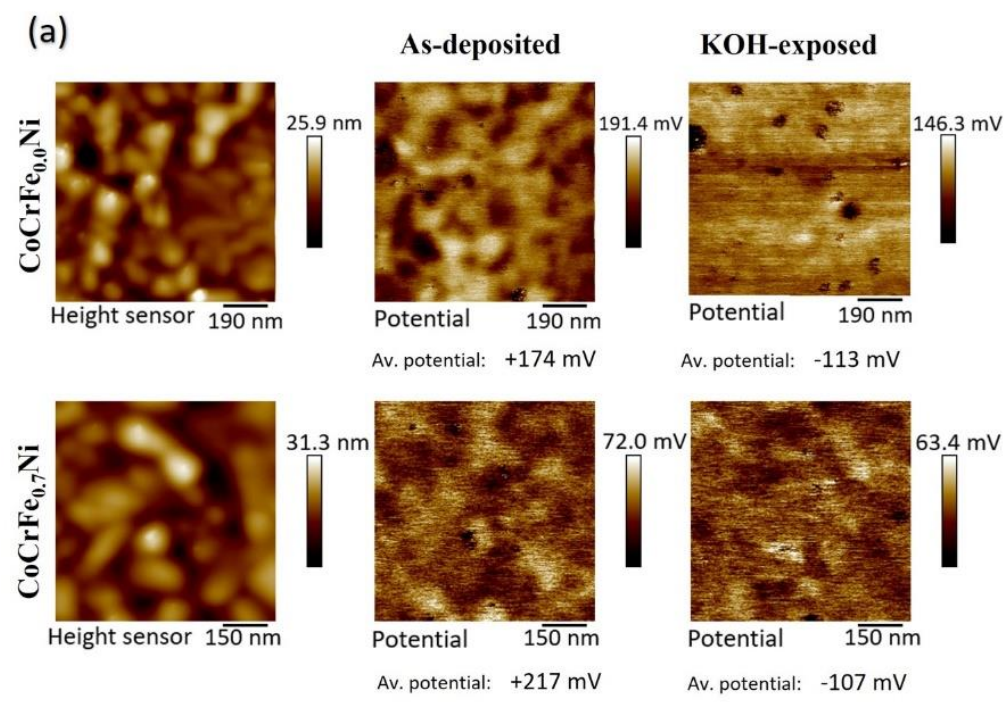

(b)

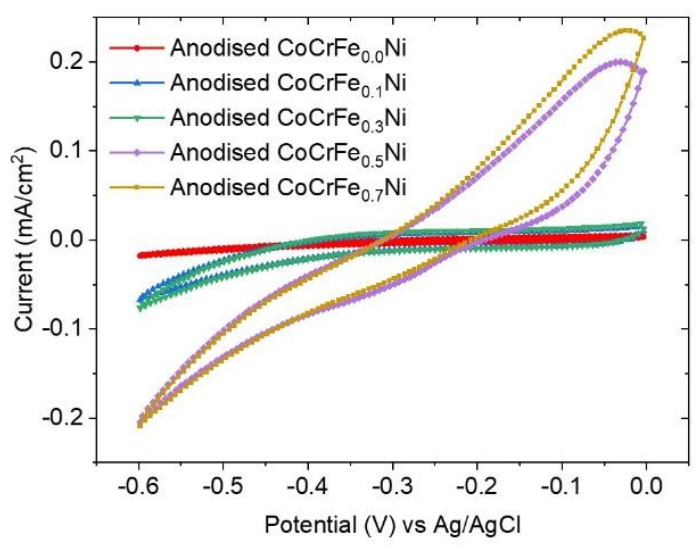

Figure 13: a) Height and potential maps obtained by SKPFM of $\mathrm{CoCrFe}_{\text {o.o }} \mathrm{Ni}$ and $\mathrm{CoCrFe}$ o. $_{7} \mathrm{Ni}$ as deposited and after exposure to $\mathrm{KOH}$, b) ORR catalysis study of anodised $\mathrm{CoCrFe}$ Ni thin films cyclic voltammograms in ORR region. 
For catalysis of ORR (Figure $13 \mathrm{~b}$ ), the films with high Fe content ( $\mathrm{x}=0.5$ 0.7 ) showed the highest current density, $0.2 \mathrm{~mA} / \mathrm{cm}^{2}$ in $\mathrm{O}_{2}$ saturated $1 \mathrm{M}$ $\mathrm{KOH}$. The higher catalytic activity was attributed to the presence of Co and Ni cations, but also Fe cations which supported the electron transfer during catalysis. Furthermore, presence of defects and lattice distortion could play a role here as well, enabling more active sites to be in contact with the electrolyte.

In this study, combining the two properties requires a trade-off, as both corrosion resistance and catalytic activity could not be optimised for the studied material system. Further investigation of the material system could lead to the optimisation of both properties and resulting in a true bifunctional new material. 
Chapter 8

\section{Future work}

During the work which led to this thesis, deeper understanding of a complex multicomponent system has been gained. Co and $\mathrm{CoCrFeNi}$ thin films have been investigated from a structural point of view, but also electrochemically in terms of catalytic activity and corrosion resistance. For future work, the study of combined catalysis and corrosion properties will remain in the centre of the doctoral studies, but additional materials and synthesis methods will be explored.

\section{Effect of other elements}

The effect of Fe was studied and raised further interest into what happens to the multicomponent system when other elements are added to it, and what their effect will be on the properties in a challenging environment. Molybdenum (Mo) for example, increases considerably the corrosion resistance of stainless steel [73], therefore investigating the addition of Mo to $\mathrm{CoCrFeNi}$ is considered as a potential future work.

\section{Deposition with HiPIMS}

In this work, many thin films syntheses have been carried out, but the effect of deposition parameters has not been studied. Synthesis of CoCrFeNi have been reported with DC-magnetron sputtering and High Power Impulse Magnetron Sputtering (HiPIMS) in hybrid mode [45]. Thin films with HiPIMS were found to be denser and have a more finegrain microstructure. Utilising this method and investigating the corrosion and catalytic properties, to finally compare them with DC-magnetron sputtering is therefore of high interest. 


\section{Replacing Cobalt}

Finally, cobalt has been a great ally in this thesis, however the ethical, economical and health aspect of this element [74] encourage the research to replace this element with even more abundant and less harmful elements, such as manganese $(\mathrm{Mn}), \mathrm{Fe}$ or copper $(\mathrm{Cu})[75,76]$. 


\section{References}

[1] J. Wisniak, The History of Catalysis. From the Beginning to Nobel Prizes, Educ. Quim. 21 (2010) 60-69. https://doi.org/10.1016/S0187893X(18)30074-0.

[2] A. Zecchina, S. Califano, From the Onset to the First Large-Scale Industrial Processes, in: Dev. Catal., 2017: pp. 1-57. https://doi.org/10.1002/9781119181286.ch1.

[3] A.D. McNaught, A. Wilkinson, IUPAC Compendium of Chemical Terminology, 2nd ed., Oxford, 1997. https://doi.org/10.1351/goldbook.C00876.

[4] Y. Wang, D.F. Ruiz Diaz, K.S. Chen, Z. Wang, X.C. Adroher, Materials, technological status, and fundamentals of PEM fuel cells - A review, Mater. Today. 32 (2020) 178-203. https://doi.org/10.1016/j.mattod.2019.06.005.

[5] Y. Li, Q. Li, H. Wang, L. Zhang, D.P. Wilkinson, J. Zhang, Recent Progresses in Oxygen Reduction Reaction Electrocatalysts for Electrochemical Energy Applications, Electrochem. Energy Rev. 2 (2019) 518-538. https://doi.org/10.1007/s41918-019-00052-4.

[6] E. Mattsson, V. Kučera, Elektrokemi och korrosionslära, Swerea KIMAB, 2009.

[7] J.W. Yeh, S.K. Chen, S.J. Lin, J.Y. Gan, T.S. Chin, T.T. Shun, C.H. Tsau, S.Y. Chang, Nanostructured high-entropy alloys with multiple principal elements: Novel alloy design concepts and outcomes, Adv. Eng. Mater. 6 (2004) 299-303. https://doi.org/10.1002/adem.200300567.

[8] B. Cantor, I.T.H. Chang, P. Knight, A.J.B. Vincent, Microstructural development in equiatomic multicomponent alloys, Mater. Sci. Eng. A. 375-377 (2004) 213-218. https://doi.org/10.1016/j.msea.2003.10.257.

[9] Y. Liang, Y. Li, H. Wang, J. Zhou, J. Wang, Co3O4 Nanocrystals on Graphene as a Synergistic Catalyst for Oxygen Reduction Reaction, Nat. Mater. 10 (2011) 780-786. https://doi.org/10.1038/nmat3087.

[10] X. Ge, A. Sumboja, D. Wuu, T. An, B. Li, F.W.T. Goh, T.S.A. Hor, Y. Zong, Z. Liu, Oxygen Reduction in Alkaline Media : From Mechanisms to Recent Advances of Catalysts, ACS Catal. 5 (2015) 4643-4667. https://doi.org/10.1021/acscatal.5b00524.

[11] J. Xiao, Q. Kuang, S. Yang, F. Xiao, S. Wang, L. Guo, Surface Structure Dependent Electrocatalytic Activity of Co 3 O 4 Anchored on Graphene Sheets toward Oxygen Reduction Reaction, Sci. Rep. 3 (2013) 1-8. https://doi.org/10.1038/srep02300.

[12] L. Zhang, C.Y. Lin, D. Zhang, L. Gong, Y. Zhu, Z. Zhao, Q. Xu, H. Li, 
Z. Xia, Guiding Principles for Designing Highly Efficient Metal-Free Carbon Catalysts, Adv. Mater. 31 (2019). https://doi.org/10.1002/adma.201805252.

[13] Z. Liu, Q. Wang, H. Miao, J. Zhao, F. Wang, Y. Xue, S. Sun, Z. Wang, J. Yuan, A new family of Mn-based perovskite (La1-xYxMnO3) with improved oxygen electrocatalytic activity for metal-air batteries, Energy. 154 (2018) 561-570. https://doi.org/10.1016/j.energy.2018.04.145.

[14] P.W. Menezes, A. Indra, D. Gonza, N.R. Sahraie, I. Zaharieva, M. Schwarze, P. Strasser, H. Dau, M. Driess, High-Performance Oxygen Redox Catalysis with Multifunctional Cobalt Oxide Nanochains : Morphology-Dependent Activity, ACS Catal. 5 (2015) 2017-2027. https://doi.org/10.1021/cs501724v.

[15] X. Huang, Y. Wang, W. Li, Y. Hou, Noble metal-free catalysts for oxygen reduction reaction, Sci. China Chem. 60 (2017) 1494-1495. https://doi.org/10.1007/s11426-017-9153-6.

[16] L. Han, S. Dong, E. Wang, Transition-Metal (Co, Ni, and Fe)-Based Electrocatalysts for the Water Oxidation Reaction, Adv. Mater. 28 (2016) 9266-9291. https://doi.org/10.1002/adma.201602270.

[17] M. Hamdani, R.N. Singh, P. Chartier, Co3O4 and Co- Based Spinel Oxides Bifunctional Oxygen Electrodes, Int. J. Electrochem. Sci. 5 (2010) 556-577.

[18] X. Deng, H. Tüysüz, Cobalt-oxide-based materials as water oxidation catalyst: Recent progress and challenges, ACS Catal. 4 (2014) 37013714. https://doi.org/10.1021/cs500713d.

[19] G. Zhang, C. Li, J. Liu, L. Zhou, One-step conversion from metalorganic frameworks to Co3O4@N-doped carbon nanocomposites towards highly efficient frameworks to Co3O4@N-doped carbon nanocomposites towards highly efficient oxygen reduction catalysts, J. Mater. Chem. A. 2 (2014) 8184-8189. https://doi.org/10.1039/c4ta00677a.

[20] M. Cassir, L. Mendoza, J. Chivot, T. Pauporté, C. Mansour, New insight in the behaviour of $\mathrm{Co}-\mathrm{H} 2 \mathrm{O}$ system at $25-150^{\circ} \mathrm{C}$, based on revised Pourbaix diagrams, Corros. Sci. 50 (2007) 62-69. https://doi.org/10.1016/j.corsci.2007.07.002.

[21] J. Xu, P. Gao, T.S. Zhao, Non-precious Co3O4 nano-rod electrocatalyst for oxygen reduction reaction in anion-exchange membrane fuel cells, Energy Environ. Sci. 5 (2012) 5333-5339. https://doi.org/10.1039/c1ee01431e.

[22] H.H. Strehblow, A. Foelske, The passivity of Co in alkaline electrolytes studied by X-ray Photoelectron Spectroscopy (XPS), in: J.. 
Sinclair, R.P. Frankenthal, E. Kálamán, W. Plieth (Eds.), Corros. Corros. Prot., 2001: pp. 9-17. https://doi.org/10.1016/00036870(73)90259-7.

[23] D. Gallant, M. Pézolet, S. Simard, Optical and physical properties of cobalt oxide films electrogenerated in bicarbonate aqueous media, J. Phys. Chem. B. 110 (2006) 6871-6880. https://doi.org/10.1021/jp056689h.

[24] M. Mathankumar, S. Anantharaj, A.K. Nandakumar, S. Kundu, B. Subramanian, Potentiostatic phase formation of $\beta-\mathrm{CoOOH}$ on pulsed laser deposited biphasic cobalt oxide thin film for enhanced oxygen evolution, J. Mater. Chem. A. 5 (2017) 23053-23066. https://doi.org/10.1039/c7ta07410g.

[25] Jones D.A, Principles and Prevention of Corrosion: Pearson New International Edition, 2nd ed., Prentice Hall, 1996.

[26] D.E. Williams, R.C. Newman, Q. Song, R.G. Kelly, Passivity breakdown and pitting corrosion of binary alloys, Nature. 350 (1991) 216-219. https://doi.org/10.1038/350216a0.

[27] E. Symniotis, Dissolution mechanism of duplex stainless steels in the active-to-passive transition range and the role of microstructure, Corrosion. 51 (1995) 571-580. https://doi.org/10.5006/1.3293616.

[28] C.O.A. Olsson, D. Landolt, Passive films on stainless steels Chemistry, structure and growth, Electrochim. Acta. 48 (2003) 10931104. https://doi.org/10.1016/S0013-4686(02)00841-1.

[29] N. Sato, An overview on the passivity of metals, Corros. Sci. 31 (1990) 1-19. https://doi.org/10.1016/0010-938X(90)90086-K.

[30] R.G. Kelly, J.R. Scully, D. Shoesmith, R.G. Buchheit, Electrochemical Techniques in Corrosion Science and Engineering, 2002. https://doi.org/10.1201/9780203909133.

[31] J. Soltis, Passivity breakdown, pit initiation and propagation of pits in metallic materials - Review, Corros. Sci. 90 (2015) 5-22. https://doi.org/10.1016/j.corsci.2014.10.006.

[32] Y.Y. Chen, T. Duval, U.D. Hung, J.W. Yeh, H.C. Shih, Microstructure and electrochemical properties of high entropy alloys-a comparison with type-304 stainless steel, Corros. Sci. 47 (2004) 2257-2279. https://doi.org/10.1016/j.corsci.2004.11.008.

[33] Z. Tang, T. Yuan, C.W. Tsai, J.W. Yeh, C.D. Lundin, P.K. Liaw, Fatigue behavior of a wrought A10.5CoCrCuFeNi two-phase highentropy alloy, Acta Mater. 99 (2015) 247-258. https://doi.org/10.1016/j.actamat.2015.07.004.

[34] Q. Wang, A. Amar, C. Jiang, H. Luan, S. Zhao, H. Zhang, G. Le, X. Liu, X. Wang, X. Yang, J. Li, CoCrFeNiMo0.2 high entropy alloy by 
laser melting deposition: Prospective material for low temperature and corrosion resistant applications, Intermetallics. 119 (2020) 1-6. https://doi.org/10.1016/j.intermet.2020.106727.

[35] A. Ayyagari, V. Hasannaeimi, H. Grewal, H. Arora, S. Mukherjee, Corrosion, Erosion and Wear Behavior of Complex Concentrated Alloys: A Review, 2018. https://doi.org/10.3390/met8080603.

[36] Y.J. Hsu, W.C. Chiang, J.K. Wu, Corrosion behavior of FeCoNiCrCux high-entropy alloys in 3.5\% sodium chloride solution, Mater. Chem. Phys. 92 (2005) 112-117. https://doi.org/10.1016/j.matchemphys.2005.01.001.

[37] Y.F. Kao, T.D. Lee, S.K. Chen, Y.S. Chang, Electrochemical passive properties of AlxCoCrFeNi ( $\mathrm{x}=0,0.25,0.50,1.00)$ alloys in sulfuric acids, Corros. Sci. 52 (2010) 1026-1034. https://doi.org/10.1016/j.corsci.2009.11.028.

[38] N. Kumar, M. Fusco, M. Komarasamy, R.S. Mishra, M. Bourham, K.L. Murty, Understanding effect of $3.5 \mathrm{wt} . \% \mathrm{NaCl}$ on the corrosion of Al0.1CoCrFeNi high-entropy alloy, J. Nucl. Mater. 495 (2017) 154163. https://doi.org/10.1016/j.jnucmat.2017.08.015.

[39] J. Wang, W. Li, H. Yang, H. Huang, S. Ji, J. Ruan, Corrosion behavior of CoCrNi medium-entropy alloy compared with 304 stainless steel in $\mathrm{H} 2 \mathrm{SO} 4$ and $\mathrm{NaOH}$ solutions, Corros. Sci. 177 (2020) 1-11. https://doi.org/10.1016/j.corsci.2020.108973.

[40] I. Moravcik, N. Sadat, A. Motallebzadeh, Materials Characterization Interstitial nitrogen enhances corrosion resistance of an equiatomic CoCrNi medium-entropy alloy in sulfuric acid solution, Mater. Charact. 172 (2021) 1-10. https://doi.org/10.1016/j.matchar.2020.110869.

[41] Y. Qiu, M.A. Gibson, H.L. Fraser, N. Birbilis, Corrosion characteristics of high entropy alloys, Mater. Sci. Technol. 31 (2015) 1235-1243. https://doi.org/10.1179/1743284715Y.0000000026.

[42] Y. Shi, L. Collins, N. Balke, P.K. Liaw, B. Yang, In-situ electrochemical-AFM study of localized corrosion of AlxCoCrFeNi high-entropy alloys in chloride solution, Appl. Surf. Sci. 439 (2018) 533-544. https://doi.org/10.1016/j.apsusc.2018.01.047.

[43] Y. Shi, B. Yang, X. Xie, J. Brechtl, K.A. Dahmen, P.K. Liaw, Corrosion of AlxCoCrFeNi high-entropy alloys: Al-content and potential scan-rate dependent pitting behavior, Corros. Sci. 119 (2017) 33-45. https://doi.org/10.1016/j.corsci.2017.02.019.

[44] L. Wang, D. Mercier, S. Zanna, A. Seyeux, M. Laurent-Brocq, L. Perrière, I. Guillot, P. Marcus, Study of the surface oxides and corrosion behaviour of an equiatomic $\mathrm{CoCrFeMnNi}$ high entropy alloy 
by XPS and ToF-SIMS, Corros. Sci. 167 (2020) 108507. https://doi.org/10.1016/j.corsci.2020.108507.

[45] A. Savan, T. Allermann, X. Wang, D. Grochla, L. Banko, Y. Kalchev, A. Kostka, J. Pfetzing-Micklich, A. Ludwig, Structure zone investigation of multiple principle element alloy thin films as optimization for nanoindentation measurements, Materials (Basel). 13 (2020). https://doi.org/10.3390/ma13092113.

[46] P. Nagy, N. Rohbeck, G. Roussely, P. Sortais, J.L. Lábár, J. Gubicza, J. Michler, L. Pethö, Processing and characterization of a multibeam sputtered nanocrystalline CoCrFeNi high-entropy alloy film, Surf. Coatings Technol. 386 (2020) 125465. https://doi.org/10.1016/j.surfcoat.2020.125465.

[47] N. Chawake, J. Zálešák, C. Gammer, R. Franz, M.J. Cordill, J.T. Kim, J. Eckert, Microstructural characterization of medium entropy alloy thin films, Scr. Mater. 177 (2020) 22-26. https://doi.org/10.1016/j.scriptamat.2019.10.001.

[48] F. Cao, P. Munroe, Z. Zhou, Z. Xie, Microstructure and mechanical properties of a multilayered $\mathrm{CoCrNi} / \mathrm{Ti}$ coating with varying crystal structure, Surf. Coatings Technol. 350 (2018) 596-602. https://doi.org/10.1016/j.surfcoat.2018.07.066.

[49] W. Huo, X. Liu, S. Tan, F. Fang, Z. Xie, J. Shang, J. Jiang, Ultrahigh hardness and high electrical resistivity in nano-twinned, nanocrystalline high-entropy alloy films, Appl. Surf. Sci. 439 (2018) 222-225. https://doi.org/10.1016/j.apsusc.2018.01.050.

[50] L. Gao, W. Liao, H. Zhang, J.U. Surjadi, D. Sun, Y. Lu, Microstructure, mechanical and corrosion behaviors of $\mathrm{CoCrFeNiAl}$ 0.3 High Entropy Alloy (HEA) films, Coatings. 7 (2017) 1-7. https://doi.org/10.3390/coatings7100156.

[51] Y. Shi, B. Yang, P.D. Rack, S. Guo, P.K. Liaw, Y. Zhao, Highthroughput synthesis and corrosion behavior of sputter-deposited nanocrystalline $\mathrm{Alx}(\mathrm{CoCrFeNi}) 100-\mathrm{x}$ combinatorial high-entropy alloys, Mater. Des. 195 (2020) 109018. https://doi.org/10.1016/j.matdes.2020.109018.

[52] C. Shang, E. Axinte, W. Ge, Z. Zhang, Y. Wang, High-entropy alloy coatings with excellent mechanical, corrosion resistance and magnetic properties prepared by mechanical alloying and hot pressing sintering, Surfaces and Interfaces. 9 (2017) 36-43. https://doi.org/10.1016/j.surfin.2017.06.012.

[53] Q. Ye, K. Feng, Z. Li, F. Lu, R. Li, J. Huang, Y. Wu, Microstructure and corrosion properties of $\mathrm{CrMnFeCoNi}$ high entropy alloy coating, Appl. Surf. Sci. 396 (2017) 1420-1426. 
https://doi.org/10.1016/j.apsusc.2016.11.176.

[54] F. Yoosefan, A. Ashrafi, S.M. Monir vaghefi, Characterization of Co$\mathrm{Cr}-\mathrm{Fe}-\mathrm{Mn}-\mathrm{Ni}$ High-Entropy Alloy Thin Films Synthesized by Pulse Electrodeposition: Part 2: Effect of Pulse Electrodeposition Parameters on the Wettability and Corrosion Resistance, Met. Mater. Int. (2020). https://doi.org/10.1007/s12540-019-00584-w.

[55] W. Wang, W. Qi, L. Xie, X. Yang, J. Li, Y. Zhang, Microstructure and corrosion behavior of $(\mathrm{CoCrFeNi}) 95 \mathrm{Nb} 5$ high-entropy alloy coating fabricated by plasma spraying, Materials (Basel). 12 (2019) 1-12. https://doi.org/10.3390/ma12050694.

[56] B.R. Braeckman, F. Boydens, H. Hidalgo, P. Dutheil, M. Jullien, A.L. Thomann, D. Depla, High entropy alloy thin films deposited by magnetron sputtering of powder targets, Thin Solid Films. 580 (2015) 71-76. https://doi.org/10.1016/j.tsf.2015.02.070.

[57] W. Li, P. Liu, P.K. Liaw, Microstructures and properties of highentropy alloy films and coatings : a review, Mater. Lett. 3831 (2018) 199-229. https://doi.org/10.1080/21663831.2018.1434248.

[58] Y. Huang, L. Chen, H. Lui, M. Cai, J. Yeh, Microstructure, hardness, resistivity and thermal stability of sputtered oxide films of $\mathrm{AlCoCrCu} 0$ . $5 \mathrm{NiFe}$ high-entropy alloy, Mater. Sci. Eng. A. 457 (2007) 77-83. https://doi.org/10.1016/j.msea.2006.12.001.

[59] V. Dolique, A.L. Thomann, P. Brault, Y. Tessier, P. Gillon, Complex structure/composition relationship in thin films of $\mathrm{AlCoCrCuFeNi}$ high entropy alloy, Mater. Chem. Phys. 117 (2009) 142-147.

https://doi.org/10.1016/j.matchemphys.2009.05.025.

[60] T. Michely, J. Krug, Pattern Formation in Multilayer Growth, in: Islands, Mounds and Atoms, 2004: pp. 121-226. https://doi.org/10.1007/978-3-642-18672-1_4.

[61] L.R. Shaginyan, V.F. Britun, N.A. Krapivka, S.A. Firstov, A. V. Kotko, V.F. Gorban, The Properties of $\mathrm{Cr}-\mathrm{Co}-\mathrm{Cu}-\mathrm{Fe}-\mathrm{Ni}$ Alloy Films Deposited by Magnetron Sputtering, Powder Metall. Met. Ceram. 57 (2018) 293-300. https://doi.org/10.1007/s11106-018-9982-0.

[62] M.K. Kini, S. Lee, A. Savan, B. Breitbach, Y. Addab, W. Lu, M. Ghidelli, A. Ludwig, N. Bozzolo, C. Scheu, D. Chatain, G. Dehm, Nanocrystalline equiatomic $\mathrm{CoCrFeNi}$ alloy thin films: Are they single phase fcc?, Surf. Coatings Technol. 410 (2021) 126945.

https://doi.org/10.1016/j.surfcoat.2021.126945.

[63] J.E. Greene, Thin Film Nucleation, Growth, and Microstructural Evolution: An Atomic Scale View, 2010. https://doi.org/10.1016/B9780-8155-2031-3.00012-0.

[64] P.B. Barna, M. Adamik, Fundamental structure forming phenomena of 
polycrystalline films and the structure zone models, Thin Solid Films. 317 (1998) 27-33. https://doi.org/10.1016/S0040-6090(97)00503-8.

[65] I. Petrov, P.B. Barna, L. Hultman, J.E. Greene, Microstructural evolution during film growth, J. Vac. Sci. Technol. A Vacuum, Surfaces, Film. 21 (2003) S117-S128. https://doi.org/10.1116/1.1601610.

[66] F. Cao, P. Munroe, Z. Zhou, Z. Xie, Medium entropy alloy CoCrNi coatings: Enhancing hardness and damage-tolerance through a nanotwinned structuring, Surf. Coatings Technol. 335 (2018) 257264. https://doi.org/10.1016/j.surfcoat.2017.12.021.

[67] W.C. Röntgen, Über eine neue Art von Strahlen, Springer, Würzburg, 1896. https://doi.org/10.1007/978-3-662-00956-7_2.

[68] M. Birkholz, Thin Film Analysis by X-Ray Scattering, WileyVCH, 2006. https://doi.org/10.1002/3527607595.

[69] M. Von Ardenee, Improvements in electron microscopes, GB511204A, 1937.

[70] K. Siegbahn, Electron spectroscopy for atoms, molecules and condensed matter - an overview, J. Electron Spectros. Relat. Phenomena. 36 (1985) 113-129. https://doi.org/10.1016/03682048(85)80013-X.

[71] H. Hertz, Über einen Einfluss des ultravioletten Lichtes auf die electrische Entladung, Ann. Phys. Chem. 267 (1887) 983-1000.

[72] C. Örnek, C. Leygraf, J. Pan, On the Volta potential measured by SKPFM-fundamental and practical aspects with relevance to corrosion science, Corros. Eng. Sci. Technol. 54 (2019) 185-198. https://doi.org/10.1080/1478422X.2019.1583436.

[73] Outokumpu, Handbook of Stainless Steel, (2013) 1-89. http://www.outokumpu.com/sitecollectiondocuments/outokumpu -stainless-steel-handbook.pdf.

[74] Cobalt: the dark side of a clean future, (n.d.). https://www.raconteur.net/corporate-social-responsibility/cobaltmining-human-rights/ (accessed December 2, 2021).

[75] C. Domínguez, F.J. Pérez-Alonso, M. Abdel Salam, J.L. Gómez De La Fuente, S.A. Al-Thabaiti, S.N. Basahel, M.A. Peña, J.L.G. Fierro, S. Rojas, Effect of transition metal (M: Fe, Co or Mn) for the oxygen reduction reaction with non-precious metal catalysts in acid medium, Int. J. Hydrogen Energy. 39 (2014) 5309-5318. https://doi.org/10.1016/j.ijhydene.2013.12.078. 
[76] A.M. Al-Enizi, M. Ubaidullah, J. Ahmed, H. Alrobei, S.M. Alshehri, Copper nickel@ reduced graphene oxide nanocomposite as bifunctional electro-catalyst for excellent oxygen evolution and oxygen reduction reactions, Mater. Lett. 260 (2019) 126969. https://doi.org/https://doi.org/10.1016/j.matlet.2019.126969. 


\section{Papers}

The papers associated with this thesis have been removed for copyright reasons. For more details about these see:

https://doi.org/10.3384/9789179292171 



\section{FACULTY OF SCIENCE AND ENGINEERING}

Linköping Studies in Science and Technology, Licentiate Thesis No. 1922, 2022 Department of Physics, Chemistry and Biology (IFM)

Linköping University

SE-581 83 Linköping, Sweden

www.liu.se 